\title{
Taxonomy, ecology and distribution of the mosquitoes (Diptera: Culicidae) of the Dutch Leeward Islands, with a key to the adults and fourth instar larvae
}

\author{
Jordy G. van der Beek \\ Naturalis Biodiversity Center, Leiden, the Netherlands \\ jordy.vd.beek@gmail.com \\ Klaas-Douwe B. Dijkstra \\ Naturalis Biodiversity Center, Leiden, the Netherlands \\ Berry B. van der Hoorn \\ Naturalis Biodiversity Center, Leiden, the Netherlands
}

Sam P. Boerlijst

Institute of Environmental Sciences, Leiden University, Leiden, the Netherlands

Loes Busscher

Naturalis Biodiversity Center, Leiden, the Netherlands

Maud L. Kok

Naturalis Biodiversity Center, Leiden, the Netherlands

Marieta A.H. Braks

Netherlands National Institute for Public Health and the Environment (RIVM), Bilthoven, the Netherlands

Francis Schaffner

Francis Schaffner Consultancy, Riehen, Switzerland

Gerald J. Davelaar

Ministry of Public Health, Social Development and Labour, Sint Maarten, Caribbean Netherlands

Maria Henry

Ministry of Public Health, Social Development and Labour, Sint Maarten, Caribbean Netherlands 


\title{
Koen Hulshof
}

Netherlands National Institute for Public Health and the Environment (RIVM), Bilthoven, the Netherlands. Public Health Department, Saba, Caribbean Netherlands

Teresa E. Leslie

Eastern Caribbean Public Health Foundation, Sint Eustatius, Caribbean Netherlands

\section{Maarten Schrama}

Naturalis Biodiversity Center, Leiden, the Netherlands

Institute of Environmental Sciences, Leiden University, Leiden, the Netherlands

\begin{abstract}
Assessing mosquito biodiversity is important for disease surveillance and ecosystem health assessments. Such studies are particularly needed in regions like the Caribbean, which have experienced a series of recent mosquito borne disease outbreaks but received little attention regarding its invertebrate biodiversity. Here, we report on results from a mosquito survey on the Dutch Leeward Islands (Sint Eustatius, Sint Maarten and Saba), carried out in April and October 2018, which is the first integrative survey since those conducted by Van der Kuyp (1947) and Wagenaar Hummelinck (1949). Moreover, we present a novel key for adults and fourth instar larvae of the mosquitoes of the Dutch Leeward Islands. Overall, eleven species were recorded, eight on Sint Maarten, five on Saba and two on Sint Eustatius. Two new potential disease vectors, Culex nigripalpus and Aedes taeniorhynchus, were recorded on Sint Maarten. One previously recorded species, $C x$. habilitator, was not retrieved from any of the islands, which is further discussed in the paper. Species indicative of natural forest which previously occurred on all three islands were absent from Sint Eustatius and Sint Maarten but still present on Saba. In contrast, species indicative of human inhabitation, Ae. aegypti and Cx. quinquefasciatus, were highly abundant on Sint Maarten and Sint Eustatius and present in low numbers on Saba. Overall, the results of this study emphasize the importance of biodiversity surveys and indicate that frequent mosquito inventories may contribute to a better understanding of mosquito community composition and distribution of potential vector species.
\end{abstract}

\section{Keywords}

biodiversity assessment - Culex nigripalpus - mosquito survey - Saba - Sint Eustatius - Sint Maarten

\section{Introduction}

Mosquitoes (Diptera: Culicidae) present a major risk for human health worldwide (WHO, 2017). Not only are they often a nuisance, but can also serve as vectors for a wide range of human and livestock pathogens causing diseases such as dengue, chikungunya, malaria, Zika, Rift Valley and West Nile fever (Rueda, 2008). As a result of anthropogenic disturbance of mosquito habitats, urbanization, international trade and travel and spread of invasive mosquitoes, the distributions of mosquito species have exhibited major changes over the past Downloaded from Bripl come4/26/2023 08:04:46AM 
decades (Lambin et al., 2010; Neiderud, 2015; Egizi et al., 2016; Eritja et al., 2017). The possible forthcoming knock-on effects on the emergence of novel pathogens highlight the importance of (more) frequent mosquito biodiversity surveys. The Caribbean is a prominent example of a region that is experiencing high levels of travel, urbanization and anthropogenic disturbance (Debrot et al., 2018) and has recently witnessed a series of major mosquito-borne disease outbreaks (i.e., the 2014 chikungunya outbreak, the 2016 Zika outbreak, several dengue outbreaks) (Matheus et al., 2012; Henry et al., 2017; Leslie et al., 2017) and the region is currently witnessing another dengue outbreak (PAHO, 2020). The importance of mosquito surveys in the Caribbean is further exemplified by lack of recent species distribution data, in combination with the dramatic loss of natural habitats (Debrot et al., 2018) and the global spread of invasive mosquitoes (Kraemer et al., 2019).

The last mosquito species inventories on Sint Eustatius, Sint Maarten and Saba were performed in 1947 (Van der Kuyp, 1948, 1949, 1954) and later by Wagenaar Hummelinck in 1949 (Van der Kuyp, 1953, 1954). Based on these surveys, Van der Kuyp (1954) listed eleven species from the islands: Aedes aegypti, Ae. busckii, Ae. taeniorhynchus, Anopheles albimanus, Culex americanus [= Cx. bisulcatus], $C x$. bahamensis, $C x$. habilitator, $C x$. quinquefasciatus, Deinocerites magnus, Psorophora pygmaea and Toxorhynchites guadeloupensis. Other islands in the Caribbean with more comprehensive and recent mosquito surveys have listed many more species, including a number of important disease vectors such as Ae. albopictus (Benedict et al., 2007) and Cx. nigripalpus (Schaffner, 2003; Mohammed et al., 2015). In total over 70 mosquito species have been recorded from the Leeward and Windward Islands (excluding Trinidad and Tobago) (Gaffigan et al., 2019). A 2010 survey of Saint Kitts, an island located only $10 \mathrm{~km}$ southeast of Sint Eustatius, recorded two species not recorded from the Dutch Leeward Islands: Ae. tortilis and Cx. nigripalpus (Mohammed et al., 2015).

Currently, mosquito research on the Dutch Leeward Islands has a strong focus on Ae. aegypti, the principle vector for chikungunya, dengue and Zika viruses, and to a lesser extent on $C x$. quinquefasciatus, a vector of West Nile virus (Couch, 2013; Leslie et al., 2014, 2017; Glandorf, 2017). When a mosquito-borne disease emerges, suppression of the vector population is in most cases the only way to respond to the outbreak. However, to be effective, recent updated information about the distribution of mosquito species as well as the occurrence and habitat use of potential vector species is essential for all three islands. For example, populations of Ae. albopictus and Ae. taeniorhynchus are present on other islands in the Caribbean region (Belkin \& Heinemann, 1976; Benedict et al., 2007; Mohammed et al., 2015), but the current distribution of these potential vector species on the Dutch Leeward Islands is not well known. Moreover, mosquito identification keys for these islands are outdated or simply not available. These knowledge gaps complicate adequate risk assessments and control efforts of species other than Ae. aegypti and highlight the need to acquire information on species' current distributions and practical mosquito identification tools (Farajollahi \& Price, 2013).

The aim of this research was to obtain a better understanding of the current distribution of various mosquito species on the Dutch Leeward Islands. To this end, we carried out an intensive one-week survey on each of the three islands (Sint Eustatius, Sint Maarten and Saba) during the dry season and a total of ten days during the wet season on Sint Maarten and Saba. We created an easy-to-use identification key for both the fourth instar larvae and the adults specifically to the species 
present on these islands based on the collected data.

\section{Material and methods}

\section{Sampling and identification}

The Dutch Leeward Islands comprise three islands in the northeastern part of Caribbean Sea: Sint Eustatius $\left(17^{\circ} 29^{\prime} \mathrm{N}, 62^{\circ} 58^{\prime} \mathrm{W}\right)$, Saba $\left(17^{\circ} 3^{\prime} \mathrm{N}, 63^{\circ} 14^{\prime} \mathrm{W}\right)$ and Sint Maarten $\left(18^{\circ} 4^{\prime} \mathrm{N}\right.$, $\left.63^{\circ} 3^{\prime} \mathrm{W}\right)$. The island of Sint Maarten consists of a Dutch and French part. Saba and Sint Eustatius are special municipalities within the Kingdom of the Netherlands and Sint Maarten is a constituent country within the Kingdom of the Netherlands. Together, these three islands have a surface area of $68 \mathrm{~km}^{2}$. Each of the islands was visited during an expedition by Naturalis Biodiversity Center in April 2018 and sampled for one week. The French part of the island, Saint Martin, was not sampled due to the limited time and administrative restrictions. Sint Maarten and Saba were revisited in October 2018 for ten days of additional sampling.

Ten trapping sites were selected in urban, semi-urban and relatively natural areas (fig. 1). Selection of these sites was based on existing vegetation maps (Verweij, 2010; De Freitas et al., 2012, 2016), knowledge on the presence of different aquatic habitats and former sampling localities of Van der Kuyp (1954). We used four different collection methods. First, at each site, a Mosquito Magnet ${ }^{\bullet}$ Independence (Woodstream Corp., USA) mosquito trap was used to trap adults. Second, Biogents (BG) Sentinel Traps ${ }^{\mathrm{Tm}}$ (Biogents AG, Germany), with the BG Lure ${ }^{\mathrm{m}}$ and a sugar-and-yeast mixture as a $\mathrm{CO}_{2}$ source were used at two to three sites per island. Specimens from all traps were collected once every 24 hours for four consecutive days. Third, at each site, we used a net and aspirator to sample free-flying adults. Finally, aquatic habitats were sampled for larvae using an aquatic net, a turkey baster and an electric pipet (Integra Biosciences ${ }^{\mathrm{TM}} \mathrm{Pi}$ petboy). The type of aquatic habitat from each larval collection site was recorded. Natural and semi-natural habitats included bromeliads, Heliconia inflorescences, tree holes, crab holes, rock and beach pools, permanent ponds, temporary ponds, and ditches. The artificial habitats include man-made containers (e.g., buckets, car tires), wells, troughs, abandoned swimming pools, and cisterns (fig. 2).

A selection of the collected mosquito larvae was reared to adult stage using a BioQuip ${ }^{\star}$ Mosquito Breeder (BioQuip Products Inc., USA). A subset of the collected adults of each species was mounted and kept for future reference. The remainder of the collected mosquito larvae was preserved in $96 \%$ ethanol. The collection has been stored at the Naturalis Biodiversity Center, formerly the National Museum of Natural History, Leiden, the Netherlands (RMNH). The mounted adults are stored under collection number RMNH. INS.1114057-4101. The larvae are stored under collection number RMNH.INS.1114151-159 and RMNH.INS.1269669-9719.

All adult mosquitoes were morphologically identified by using newly developed keys (included after the Discussion), which were based on available specimens, species descriptions, and pre-existing identification keys for the region (such as: Lane, 1953; Van der Kuyp, 1954; Pratt, 1969; Belkin et al., 1970; Darsie et al., 2010; Gustave et al., 2018). All morphospecies from the sites were DNA barcoded as mini-barcodes for MT-CO1 by using a Culicid-specific primer (Boerlijst et al., 2019; Krol et al., 2019). Morphological identifications were checked by blasting the barcodes against the Barcode of Life Data (BOLD) System (version 4) and a reference database extracted from a small collection of pinned adults from Guadeloupe provided by one of the authors (FS) (RMNH.INS.1114107-134). All 


\section{Sint Maarten}

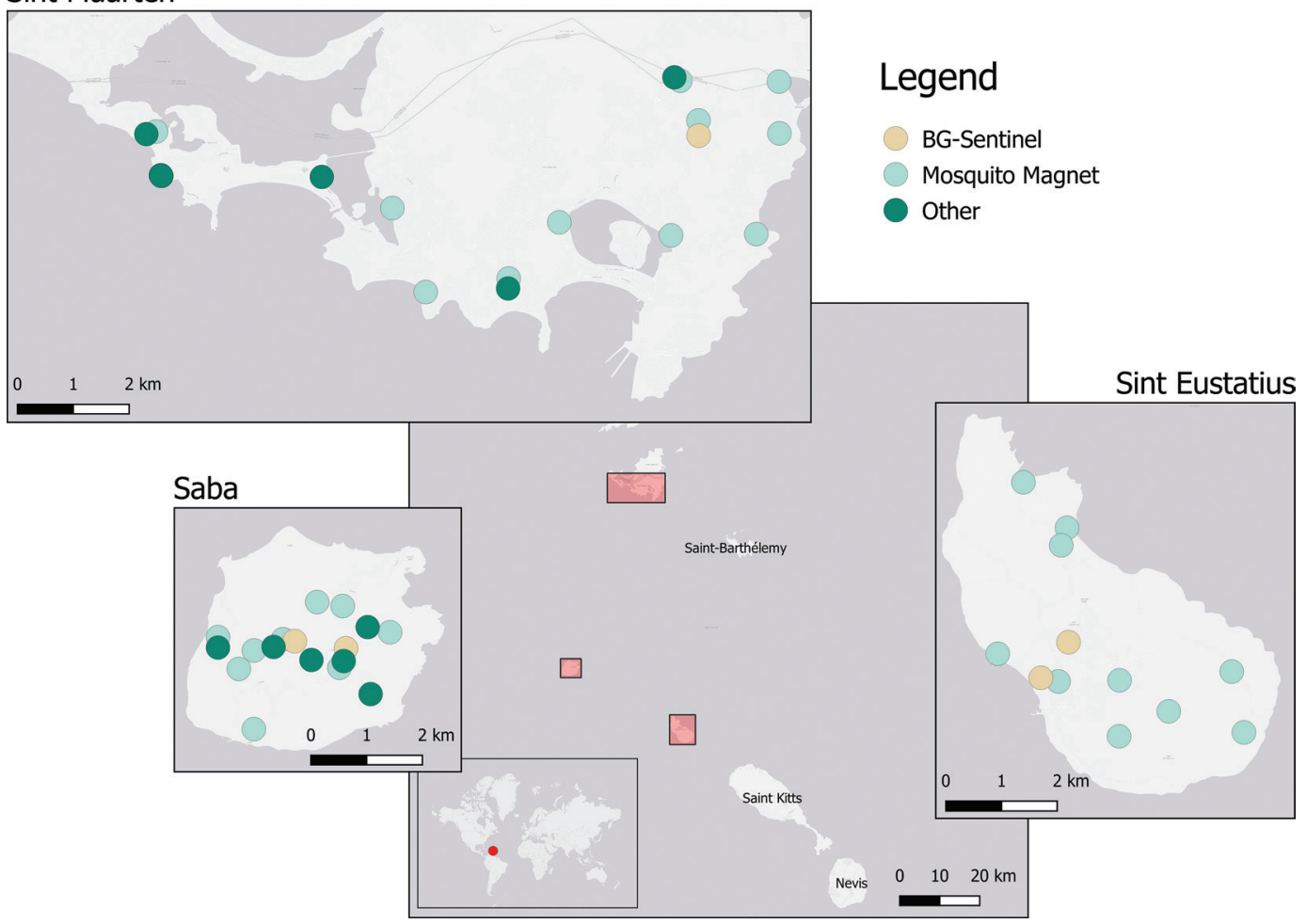

FIGURE 1 Sample sites of mosquitoes on Sint Eustatius, Saba and Dutch Sint Maarten during the 2018 Naturalis expeditions. The sampling methods referred to as "Other" comprise of different manual methods to sample adults and larvae. Sites with a BG-sentinel trap or other sampling method that was within 50 m of a Mosquito Magnet site are not separately shown on this map. Map created with QGIS, basemap. (C) OpenStreetMap contributors and the GIS user community.
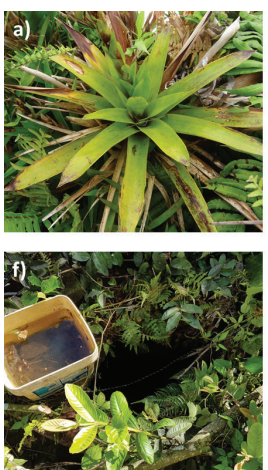
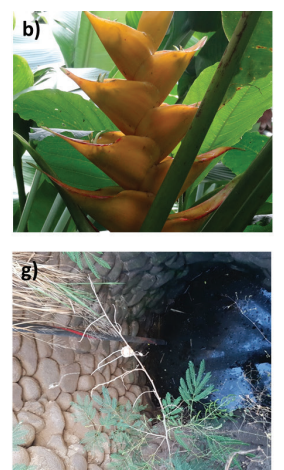
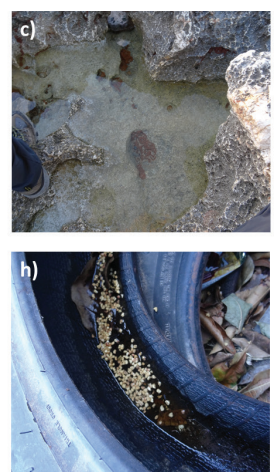
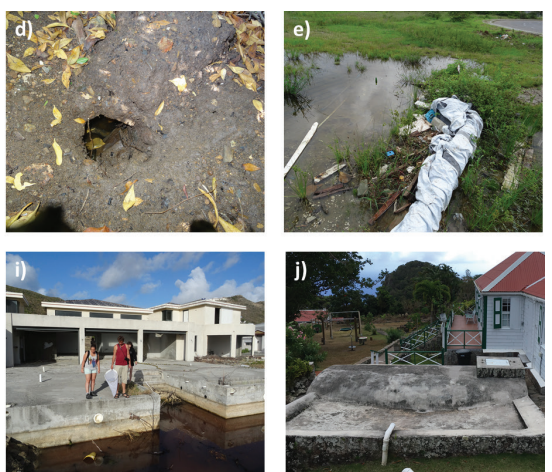

FIGURE 2 Different habitat types that were sampled during the 2018 survey. Natural habitats: a) Bromelias, b) inflorescences of Heliconia sp. c) rock pool/beach pool, d) crab hole; Semi-natural habitats: e) temporary/permanent pond, Artificial habitats: f) bucket, g) well, h) car tire, i) abandoned swimming pool, j) cistern. Photos courtesy of K.-D.B. Dijkstra, J.G. van der Beek and K. Hulshof. 
extracted reference barcodes are available in the "Culicidae Caribbean (MEDLI)" project on BOLD (www.boldsystems.org).

To inspect whether the mosquito species communities differ between the islands and whether the different habitat types contain different mosquito communities, nonmetric multidimensional scaling (NMDS) analyses were conducted in RStudio (version 1.2.5019) with $\mathrm{R}$ version 3.6.1 (supplementary figs. S1 and $\mathrm{S}_{2}$ ). Results are discussed in the (species specific) sections below.

\section{Taxonomic treatment}

Species names follow the generic and subgeneric classification of Harbach \& Howard (2007), except for the species from the tribe Aedini (in this case all Aedes and Psorophora species). Nomenclature of the latter follows Wilkerson et al. (2015), where most genera are returned to sub-generic status.

\section{Construction of morphological identification keys}

To facilitate identification, we constructed a dichotomous, literature-based identification key for the mosquitoes of the Dutch Leeward Islands, which is included after the Discussion. Aside from the species recorded from the islands, the invasive mosquito Ae. albopictus is included, because it is likely to spread across the Caribbean, as well as Ae. tortilis, a species present on the neighboring islands.

The key is based on previous keys from the Caribbean region (Lane, 1953; Van der Kuyp, 1954; Pratt, 1969; Belkin et al., 1970; Darsie et al., 2010; Gustave et al., 2018). Additional characters were added from species (re)descriptions, standard reference works and (sub)generic revisions (Bram, 1967; Berlin, 1969a; Berlin \& Belkin, 1980). Where possible, the key was improved after examination of collection material from the 2018 survey and material already present in the collection of Naturalis Biodiversity Center (Leiden, The Netherlands).

\section{Results}

A total of 831 adult mosquitoes was trapped and examined during the 2018 survey. The number of larvae was not assessed, because only a subsample of larvae was collected from each of the habitats. Eleven species of mosquitoes, belonging to six genera, were recorded on all islands combined. Eight species were recorded from Sint Maarten, five from Saba and only two from Sint Eustatius (table 1). The most collected species were $C x$. quinquefasciatus (56\% of adults) and Ae. aegypti (35\% of adults). Aedes taeniorhynchus and $C x$. nigripalpus were recorded for the first time for the island of Sint Maarten.

There were some notable differences in larval habitat use between species (table 2; supplementary figs. S1 and S2). Six species were observed only in natural and semi-natural habitats: $C x$. bisulcatus; $C x$. habilitator, $C x$. nigripalpus, De. magnus, Ps. pygmaea and Tx. cf. guadeloupensis. Some of these species were observed in a single habitat type only: $C x . b i$ sulcatus only occurred in plant containers, and De. magnus in crab holes. None of the observed species were completely restricted to artificial habitats, although the occurrence in semi-natural habitats was rare for the larvae of Ae. aegypti and Cx. quinquefasciatus (less than $9 \%$ of positive sites).

\section{Discussion}

Historically, eleven mosquito species were recorded on the Dutch Leeward Islands. During the 2018 survey, ten of these were retrieved. In addition, Ae. taeniorhynchus and $C x$. nigripalpus were recorded for the first time for Sint Maarten. For each of the separate islands the percentage of retrieved species was markedly lower than in the survey by Van der Kuyp (1954). Five $(83 \%)$ of the previously recorded species were found again on Saba, six $(75 \%)$ 
TABLE 1 Overview of the mosquito species of the Dutch Leeward Islands. This table includes the results of the 2018 Naturalis survey $(\bullet)$ as well as that of Van der Kuyp (1954) (०)

\begin{tabular}{|c|c|c|c|}
\hline & Sint Maarten & Saba & Sint Eustatius \\
\hline Aedes (Howardina) busckii (Coquillett, 19o6) & & $\bullet$ & o \\
\hline Aedes (Ochlerotatus) taeniorhynchus (Wiedemann, 1821) & $\bullet 1$ & $\bullet^{2}$ & \\
\hline Aedes (Stegomyia) aegypti (Linnaeus, 1762) & $\bullet$ & $\bullet$ & $\bullet$ \\
\hline Anopheles (Nyssorhynchus) albimanus Wiedemann, 1820 & $\bullet$ & & \\
\hline Culex (Culex) bahamensis Dyar \& Knab, 1906 & $\bullet$ & & ० \\
\hline Culex (Culex) habilitator Dyar \& Knab, 1906 & $\circ^{3}$ & & \\
\hline Culex (Culex) nigripalpus Theobald, 1901 & $\bullet 1$ & & \\
\hline Culex (Culex) quinquefasciatus Say, 1823 & $\bullet$ & $\bullet$ & $\bullet$ \\
\hline Culex (Micraedes) bisulcatus (Coquillett, 19o6) & $\circ$ & $\bullet$ & 0 \\
\hline Deinocerites magnus (Theobald, 1901) & $\bullet$ & & \\
\hline Psorophora (Grabhamia) pygmaea (Theobald, 1903) & $\bullet$ & & \\
\hline
\end{tabular}

${ }^{1}$ New record for Sint Maarten.

${ }^{2}$ Record by Cornel et al. (2020).

${ }^{3}$ Doubtful record, see the discussion.

TABLE 2 Overview of the habitats used by the different mosquito species of the Dutch Leeward Islands, based only on data from the islands of Sint Eustatius, Sint Maarten and Saba. The table includes the results of the 2018 Naturalis survey $(\bullet)$ as well as that of Van $\operatorname{der} \operatorname{Kuyp}(1954)(\circ)$

\begin{tabular}{|c|c|c|c|c|c|c|c|c|c|c|}
\hline & \multicolumn{8}{|c|}{ Natural and semi-natural habitats } & \multicolumn{2}{|c|}{ Artificial habitats } \\
\hline & 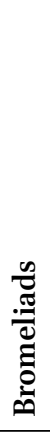 & 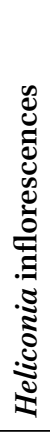 & 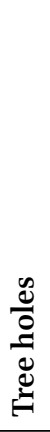 & $\frac{\frac{\mathscr{d}}{0}}{\frac{\pi}{0}}$ & $\begin{array}{l}\frac{n}{0} \\
0 \\
0 \\
\\
0 \\
0\end{array}$ & 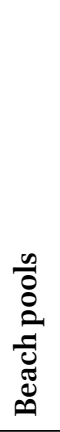 & 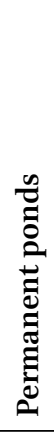 & 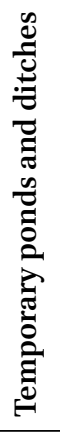 & 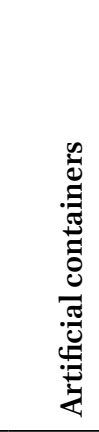 & 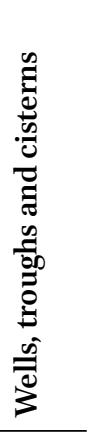 \\
\hline Ae. aegypti & & & & & O & & & & $\bullet$ & $\bullet$ \\
\hline Ae. busckii & & $\bullet$ & O & & & & & & $\bullet$ & \\
\hline Ae. taeniorhynchus & & & & & & & & $\bullet$ & & O \\
\hline An. albimanus & & & & & & & $\bullet^{1}$ & & & 0 \\
\hline Cx. bisulcatus & $\bullet$ & & & & & & & & & \\
\hline Cx. bahamensis & & & & & $\bullet$ & O & & & & $\bullet$ \\
\hline Cx. habilitator ${ }^{2}$ & & & & O & & & & & & \\
\hline Cx. nigripalpus & & & & & & & $\bullet$ & $\bullet$ & & \\
\hline Cx. quinquefasciatus & & & & & & & $\bullet$ & & $\bullet$ & $\bullet$ \\
\hline De.magnus & & & & $\bullet$ & & & & & & \\
\hline Ps. pygmaea & & & & & & & & $\bullet$ & & \\
\hline Tx. cf. guadeloupensis & $\bullet$ & & $\bullet$ & & & & & & & \\
\hline
\end{tabular}

${ }^{1}$ No larvae were found during this survey. This habitat type represents the most prominent larval habitat of this species on neighboring islands.

${ }^{2}$ Doubtful record, see the discussion. 
on Sint Maarten and two (40\%) on Sint Eustatius. The vast majority of adults trapped with the Mosquito Magnet ${ }^{\bullet}$ belonged to the group of 'indicators of anthropogenic activity', which suggests that for surveys on these islands a combination of larval sampling and hand-sampling of adult mosquitoes at dawn may be more effective than using traps.

Although we visited the island in the same month (April) as Van der Kuyp, we are not able to compare mosquito abundances between the 1947 and 2018 surveys. Van der Kuyp did not mention much about his sampling strategy and the number of sampled individuals is lacking for most of the mosquito species.

Below, we discuss habits, occurrences and changes therein for each species separately, in alphabetic order. Moreover, we discuss the potential methodological shortfalls of this study, the overall changes in mosquito communities for each of the islands, and the overall patterns of change.

\section{Remarks on species}

Aedes (Howardina) busckii (Coquillett, 1906) Aedes busckii was recorded from a tree hole on Sint Eustatius (Van der Kuyp, 1948, 1954) and recorded as the most abundant mosquito species $(71 \%)$ in water held by Heliconia caribaea inflorescences on Saba (Bass \& Bass, 2011). Larvae were found both in Heliconia bracts and in rainwater on the lid of a rain barrel on Saba (Bud's Mountain Trail and Crispeen Trail, approx. $\left.17^{\circ} 37^{\prime} 50^{\prime \prime} \mathrm{N}, 63^{\circ} 14^{\prime} 30^{\prime \prime} \mathrm{W}\right)$. We did not observe Ae. busckii on Sint Eustatius, likely as a result of the lack of water in tree holes and the absence of Heliconia flowers during our visit.

The distribution of Ae. busckii is restricted to the Lesser Antilles, from Saba to Grenada. Berlin (1969b) noted that the northern populations (Sint Eustatius to Guadeloupe) differ from the southern ones (which includes the type locality: Dominica [erroneously stated to be San Domingo in original description (fide Howard et al., 1917)]). Northern adults have a larger white ring on segment 3 of the hind tarsus, while the larvae have a larger patch of comb scales and pecten teeth that reaches as far as the siphonal hairs (Berlin, 1969b). The male genitalia of the northern population differ in having more hairs and a broader aedeagus, with distinct lobes at the tip (Berlin, 1969b). The Saba population shows probably northern character states, but this cannot be confirmed because the diagnostic characters are not quantified in literature and material from its southern distribution was not available for comparison to the authors. Whether there is genetic differentiation is not known as barcodes from southern populations are unavailable.

Interestingly, Ae. busckii larvae were not found in bromeliads on Saba (this study and Richardson \& Richardson, 2014) and have only rarely been found there on other islands (Berlin, 1969b). Whether this is due to differences in water quality, competition with $C x$. bisulcatus or predator avoidance (e.g., Tx. guadeloupensis) is unclear.

\section{Aedes (Ochlerotatus) taeniorhynchus}

(Wiedemann, 1821)

This is the first time that Ae. taeniorhynchus is recorded on Sint Maarten. Adults of this species were collected in the Belvedere district near the French border next to an open drain and a small pond, close to a marsh. Van der Kuyp (1954) reported that this species often co-occurs with Anopheles species. Interestingly, we trapped Ae. taeniorhynchus in conjuction with An. albimanus at this site. Furthermore, larvae were collected at a different site close to Mullet Bay Golf Course from stagnant rainwater on the course. This location is close to the American University building of the Caribbean School of Medicine where adults were trapped by students (Colin Michie, pers. 
comm., 27 July 2018). Van der Kuyp $(1953,1954)$ also reports Ae. taeniorchynchus from a well at Spring Bay, Saba. Despite our best efforts, both in April and October we were not able to find this species there again. However, during a subsequent study, a female of this species was trapped with a BG-Sentinel Trap in the harbour of Saba by one of the authors (Cornel et al., 2020) (Yoosook Lee, pers. comm., 1 September 2019), which shows that this species is still occurring on the island.

Antillean adults of Ae. taeniorhynchus are described to be darker overall than their continental conspecifics (Belkin et al., 1970). This is most pronounced in the reduced white rings on the hind tarsus, with only a very small basal white ring on the $5^{\text {th }}$ segment. Previously, these dark specimens have been described by Giles (1904) and Ludlow (1905) as two separate species: Ae. niger and Ae. portoricensis. Howard et al. (1917) noted the absence of differences in the male genitalia and larvae between both forms, and suggested the dark form was a "geographic race" of $A e$. taeniorhynchus.

Aedes (Ochlerotatus) tortilis (Theobald, 1903) Aedes tortilis has never been recorded on any of the Dutch Leeward Islands, but occurs throughout the Lesser Antilles (Arnell, 1976) and is present on the neighboring Virgin Islands (Dyar, 1922) and Saint Kitts (Mohammed et al., 2015). Therefore, it is likely that this species is present, on one of the Dutch islands and it is therefore included in the adult and larval identification keys. The larval habitats generally occur in temporary or semipermanent fresh to brackish groundwater pools (Arnell, 1976), conditions that are omnipresent on Sint Maarten.

Aedes (Stegomyia) aegypti (Linnaeus, 1762) The invasive Ae. aegypti was probably introduced in the $16^{\text {th }}$ century (Lounibos, 2002). It breeds in artificial containers and feeds mainly on human blood and is therefore mainly found close to habitation (Harrington et al., 2001). It is the main vector for a number of arboviruses in the Caribbean causing dengue, chikungunya and Zika (Leslie et al., 2014, 2017). As expected, we found Ae. aegypti present in urban habitats on all three islands. We also found Ae. aegypti in high densities in two remote old wells on Sint Eustatius (Venus Bay Road, $17^{\circ} 30^{\prime} 17.8^{\prime \prime}$ N, $62^{\circ} 5^{8} 59.4^{\prime \prime}$ W; Smoke Alley [near Fort Rotterdam], $17^{\circ} 29^{\prime} 13.1^{\prime \prime ~ N, ~}$ $62^{\circ} 59^{\prime} 36.0$ " W). One of these wells had a relatively high salinity of $7 \%$, which has been shown to be well within the tolerance range of Ae. aegypti (De Brito Arduino et al., 2015). Verdonschot and Besse-Lototskaya (2014) concluded from a meta-analysis of 62 dispersal studies that Ae. aegypti can cover maximally distances of $2.5 \mathrm{~km}($ mean $=333 \mathrm{~m})$. Reiter et al. (1995) reported that furthest Ae. aegypti post-blood meal flight was $441 \mathrm{~m}$ (mean $=181$ $\mathrm{m})$. In a $200 \mathrm{~m}$ radius around the wells, only one or two residences are present, whereas goats were extremely abundant on this part of this island. The fact that post-blood meal flights over $200 \mathrm{~m}$ are exceptional and densities of adult mosquitoes at both sites were exceptionally high suggests that Ae. aegypti at these localities may be partly feeding on nonhuman hosts. Other studies have shown that the percentage of Ae. aegypti that were bloodfed on humans varies from $76.2 \%$ in rural Puerto Rico (Barrera et al., 2012), where other hosts were mainly dogs, but also on cats, horses, and chickens, to $99.1 \%$ in Thailand (Ponlawat \& Harrington, 2005). On Sint Eustatius, goats and sheep are very abundant at these sites. However, further research is needed to examine the origin of the blood meals.

Aedes (Stegomyia) albopictus (Skuse, 1894) Another invasive mosquito species, Ae. albopictus is present on other Caribbean islands such as Barbados, Cayman Islands, Cuba, Dominican Republic and Trinidad, but has 
not yet been confirmed for the three focal islands (Benedict et al., 2007). Due to intensive travel and transport to the Dutch Leeward Islands, establishment seems probable. We therefore included this species in both the adult and larval identification keys. At the time of writing there is no definitive evidence to support the presence of Ae. albopictus on the Dutch Leeward Islands.

\section{Anopheles (Nyssorhynchus) albimanus}

Wiedemann, 1820

Anopheles albimanus had been recorded once as larvae from a well in Rockland on Sint Maarten by Van der Kuyp (1953, 1954). During our survey, adults were caught in Belvedere district near the French border, which is approximately two kilometers from the place where Van der Kuyp observed this species.

Van der Kuyp (1954) mentioned the finding of An. "tarsimaculatus" [sic] on French Saint Martin by B.J. Emanuels in the 1920s. At the time, the name tarsimaculatus was invalidly proposed as emendation for An. albipes by Goeldi (1905). Both names are now recognized as synonyms of An. albimanus (fide Rozeboom \& Gabaldon, 1941). We assume Emanuels' finding of An. albimanus to be correct because there are no other Anopheles species present on the neighboring islands, and Faran (1980) also recorded this species from French Saint Martin.

\section{Culex (Culex) bahamensis Dyar \& Knab, 1906} Culex bahamensis was collected in large numbers at two brackish water sites on Sint Maarten (Lowlands, $18^{\circ} 02$ '28. $7^{\prime \prime} \mathrm{N}, 63^{\circ} 07^{\prime}$ 28.2" W, in saltwater rockpools; Guana Bay, $18^{\circ} 01^{\prime} 54.6^{\prime \prime} \mathrm{N}, 63^{\circ} 01^{\prime} 25.9^{\prime \prime} \mathrm{W}$, in a puddle on the concrete driveway of an unfinished and abandoned mansion).

This is in line with all the findings of Van der Kuyp (1948, 1949, 1954), which are also from brackish water. However, this species has also been recorded from fresh water and is occasionally found in artificial containers on other islands (Belkin et al., 1970). On Sint Eustatius, this species had previously been recorded from a well near 'Oranjebaai' by Van der Kuyp (1948, 1949, 1954). Despite our effort to sample from the exact same well $\left(17^{\circ} 29^{\prime} 13.1^{\prime \prime}\right.$ $\mathrm{N}, 62^{\circ} 59^{\prime} 36.0$ " W), the species was not found. Instead, we trapped adults of Ae. aegypti at the well and collected large numbers of larvae from the slightly brackish well water.

Culex (Culex) habilitator Dyar en Knab, 1906 Although Van der Kuyp $(1948,1949,1954)$ reported $C x$. habilitator from land crab holes on Sint Maarten (Rolandus Channel and Lower Princess Quarter) often together with De. magnus, we did not find any. The identification of this species is problematic as adults look very similar to $C x$. bahamensis, whereas the larvae resemble $C x$. nigripalpus. Despite the fact that Van der Kuyp collected both larvae and adults, and therefore identification should be easy, his description of the larvae does not agree with diagnostic characters described by Bram (1967). The larvae of Van der Kuyp have "anal gills, about as long as the segment, with blunt tips" and are pictured with a double apical tuft on the siphon; the gills should be short, pointed, and the tuft should be triple. This suggests that the larvae actually fit the description of $C x$. nigripalpus, a species that is sometimes found in crab holes as well (Belkin et al., 1970). Van der Kuyp's adults do however resemble the few available descriptions of $C x$. habilitator (Dyar, 1928; Lane, 1953 [erroneously noted as "habilitador" [sic]]; Bram, 1967). The fact that $C x$. habilitator is present on many of the Lesser Antillean islands (Belkin \& Heinemann, 1975, 1976; Schaffner, 2003) suggests that this species may be present on the Dutch Leeward Islands too. To determine whether Van der Kuyp's records really represent this species, a reanalysis of the original material stored in the 
Smithsonian Institution is needed (National Museum of Natural History, Washington D.C., USA-NMNH).

Culex (Culex) nigripalpus Theobald, 1901

Culex nigripalpus has been recorded for the first time from the Dutch Leeward Islands in our survey at two localities on Sint Maarten

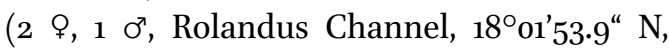
$63^{\circ} 02$ ' 17.7 " W, April 20 ${ }^{\text {th }}, 2018$; 1 O, Belvedere, $18^{\circ} 03^{\prime} 26.9^{\prime \prime} \mathrm{N}, 63^{\circ} 02^{\prime} 14.4^{\prime}$ W, April 20 ${ }^{\text {th }}, 2018$, next to an open drain and small pond).

When Van der Kuyp sampled the Rolandus Channel in the late 1940s, $C x$. nigripalpus was not observed (Van der Kuyp, 1953, 1954), but $C x$. habilitator was recorded at this locality. The larvae of that species look very similar to those of $C x$. nigripalpus. Therefore, $C x$. nigripalpus may have been present during Van der Kuyp's inventory but was misidentified as $C x$. habilitator.

Culex (Culex) quinquefasciatus Say, 1923

Culex quinquefasciatus is strongly associated with urbanization, as it prefers artificial containers and polluted groundwater as larval habitats (Belkin et al., 1970). The species had been already introduced into the New World from Africa before 1800 (Belkin, 1962). As expected, $C x$. quinquefasciatus was present in urban habitats on all three islands. Because of the complexity of the $C x$. pipiens complex, of which $C x$. quinquefasciatus is a member, we did not delve deeper into the identification of this species on the Dutch Leeward Islands. All (sub)tropical populations from the New World have been considered to be $C x$. quinquefasciatus although Culex pipiens s.s. was also introduced to the Americas (Harbach, 2012). The two lack clear morphological differences and interbreed within their non-native range (Cornel et al., 2012). Only a genetic study of the Caribbean populations can reveal their identity.
Culex (Culex) bisulcatus (Coquillett, 1906)

Culex bisulcatus was synonymized with $C x$. americanus (NeveuLemaire, 1902) by Dyar (1928), but restored by Stone (1967) as a valid species. Berlin (1969a: 30-34) re-analyzed the material of Van der Kuyp and concluded that the material belongs to $C x$. bisulcatus. Material from the Leeward Islands matches the topotypic material from Guadeloupe, except for the number of setae on the $9^{\text {th }}$ tergite lobe of the male genitalia, which are more numerous on those of the Leeward Islands (Berlin, 1969a). Up to now, this taxonomic problem has not been addressed using modern genetic analysis. Due to a lack of genetic reference material, we were unable to address this problem in the current study. In this study, larvae of $C x$. bisulcatus were only observed in bromeliads on Saba. The species was previously also recorded on Sint Eustatius and Sint Maarten (Van der Kuyp, 1948, 1949, 1953, 1954), but was not retrieved from these locations despite considerable efforts. There are two possible explanations for this. First, climatological conditions were suboptimal for this species during our visit. This may be an explanation for Sint Eustatius, where most of the sampled phytotelmata were dry in comparison to the summer when they may be filled with water. Second, the number of bromeliads was strongly reduced due to urbanization and recent hurricanes on Sint Maarten (Richardson et al., 2015), as we observed many bromeliads on fallen branches. Despite sampling dozens of bromeliads on Sint Peter Hill and the South Reward, the only remaining habitat on Sint Maarten, no larvae were found.

\section{Deinocerites magnus (Theobald, 1901)}

Adults of De. magnus were collected in or close to crab holes at several localities on Sint Maarten. Van der Kuyp (1948, 1949, 1953, 1954) identified this species as De. cancer, but it was later identified as De. magnus by Adames 
(1971) after examining Van der Kuyp's original material. Deinocerites cancer has not been recorded from other islands of the Lesser Antilles (Gaffigan et al., 2019).

\section{Psorophora (Grabhamia) pygmaea}

(Theobald, 1903)

Van der Kuyp $(1953,1954)$ recorded Ps. pygmaea from the Rolandus Channel on Sint Maarten. During the 2018 survey, this species was not observed at this location, but was found in shallow ponds on a flooded lawn in the Belvedere district, but only during the rainy season. The species is known to require recently flooded plains for their eggs to hatch (Belkin et al., 1970), which explains why they were not observed during the dry season. Sint Maarten has lowlands with poorly drained mineral soils, in strong contrast with the soils of Sint Eustatius and Saba which consist of better drained sandy-loam and are more steep (Veenenbos, 1955). This makes it unlikely that rainwater pools form long enough for the larvae of Ps. pygmaea to develop on Sint Eustatius and Saba.

Toxorhynchites (Lynchiella) cf. guadeloupensis (Dyar \& Knab, 1906)

During the 2018 survey, two Toxorhynchites larvae were collected on Saba. A fourth instar larva was sampled from a tree hole next to

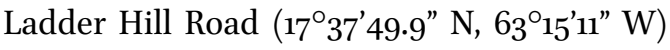
and an early instar larva was collected from a bromeliad next to Bud's Mountain Trail (1 $7^{\circ} 37^{\prime}$ $\left.\mathrm{N}, 63^{\circ} 14^{\prime} \mathrm{W}\right)$. The characteristics of these specimens are in accordance with the ones mentioned in Augier et al. (2003). Therefore, we assume that these specimens belong to $T x$. guadeloupensis. This is in line with the finding of a Tx. quadeloupensis larva in July 1949 by Van der Kuyp (1954) in a bromeliad on Mount Scenery. However, both of our specimens have a ventral brush on the 1oth segment consisting of 9-10 tufts, which would suggest that the specimens are more similar to those of $T x$. portoricensis (as mentioned in the identification key by Belkin et al. (1970)). This may indicate that Saba hosts two Toxorhynchites species. On Montserrat where these two species of Toxorhynchites occur, Tx. portoricensis occurs only in tree holes and Tx. guadeloupensis only in bromeliads (Belkin et al., 1970). To further address this issue and identify the Saba species with absolute certainty, more reference material and additional molecular work are required.

\section{Overall shifts in mosquito community composition on Sint Maarten between 1947 and 2018}

Due to its different geological history and natural habitats, the mosquito fauna of Sint Maarten contains a number of species indicative of lowland freshwater or brackish habitats, including An. albimanus, Ps. pygmaea, and $C x$. bahamensis. Well-draining soils, permanent high groundwater levels and an abundance of land crabs provides the ideal habitat for De. magnus in almost all lowland areas on the island. In addition, during the 2018 survey, we observed $C x$. nigripalpus and Ae. taeniornhynchus in these habitats, both of which we report new for the island of Sint Maarten. There were a number of other notable differences between 1947 and 2018 . First, the 'indicators of anthropogenic activity' such as Ae. aegypti and Cx. quinquefasciatus were very abundant and likely increased due to a combination of urbanization as a result of major population growth (1951: 1,478 inhabitants vs 2014: 40,552 inhabitants) and devastation by hurricanes. With increasing urbanization, most of the indigenous forest is lost and consequently also species associated with these habitats, such as Cx. bisulcatus.

\section{A tale of two islands}

Despite the similarity in geology and natural history of the islands of Sint Eustatius and 
Saba, we observed a striking difference in the current species communities compared with those in 1947. Although both 'natural forest indicators' (Cx. bisulcatus and Ae. busckii) were present on both islands during the 1947 survey (carried out in the same time of the year; Van der Kuyp 1954), they are currently absent from Sint Eustatius but relatively abundant on Saba. This difference may partly be due to limitations in sampling effort on Sint Eustatius, where we have not managed to sample all bromeliads on the rim of the volcano and the sampling campaign lasted only one week during the dry season. This makes it difficult to draw firm conclusions on the actual loss of species. Alternatively, it may be also be caused by a more pronounced effect of climate change on the natural forest on the volcano of Sint Eustatius (621 $\mathrm{m}$ asl) compared to Saba (872 $\mathrm{m}$ asl), which may have caused the potential mosquito habitat to have shifted beyond the altitude of the volcano on Sint Eustatius. Indeed, we have not observed any water filled phytotelmata on Sint Eustatius, whereas on Saba most phytotelmata contained water. To test this hypothesis and to confirm if these species are really absent from Sint Eustatius, additional sampling is required. The second aspect regarding the difference between these islands is the fact that adults of Ae. aegypti and Cx. quinquefasciatus were collected much more frequently on the island of Sint Eustatius (100\% of all collections on this island) than on Saba (3.6\% of all collections on this island). This may be due to the fact that the vector control unit is able to visit every household on average every 40 days on Saba which is not the case on Sint Eustatius. Sint Eustatius has a population twice the size of Saba, yet Saba's vector control unit is twice the size of that in Sint Eustatius, as a result of budgetary constraints. In addition, Ae. aegypti has colonized some of the more remote fresh and brackish water wells on Sint Eustatius, including one site which was previously inhabited by $C x$. bahamensis, whereas this species was absent from the more remote wells and cisterns on Saba. Overall, we conclude that the striking dissimilarity in mosquito species composition between the islands of Sint Eustatius and Saba may be a combination of under-sampling, loss of suitable habitat, and a difference in mosquito control approach.

\section{Key to the adults}

Morphological identification key to the adult mosquitoes of the Dutch Leeward Islands.

1 Proboscis stiff; bent downwards; narrowed towards tip

..... Toxorhynchites cf. guadeloupensis Proboscis flexible; not bent downwards; equal in width or swollen at tip

2(1) Wings veins with spots of dark and light scales. Scutellum evenly rounded on hind margin; with hairs evenly spaced. Female: palpi about as long as the length of proboscis. Male: palpi club-shaped.......Anopheles albimanus Wing veins with only dark scales. Scutellum with three lobes on hind margin; each lobe bearing a separate group of hairs. Female: palpi less than half the length of the proboscis. Male: tips of palpi sometimes swollen, but never club-shaped .3

3(2) Postspiracular hairs present. Female: apex of abdomen blunt, i.e. segment 7 not narrowed, segment 8 short, but not retracted

Postspiracular hairs absent. Female: apex of abdomen more or less pointed, i.e. segment 7 narrow, segment 8 short and retracted.

4(3) Prespiracular hairs present ...................... Psorophora pygmaea

Prespiracular hairs absent ......................5 
5(4) Tarsal segments of hind leg completely dark scaled Aedes tortilis Tarsal segments of hind leg with at least some white scaled markings.......6

6(5) Upperside abdomen dark without basal white bands. Aedes busckii

- Upperside abdomen dark with basal white bands

7(6) Proboscis with median white ring........... Aedes taeniorhynchus

- $\quad$ Proboscis entirely dark, or with a few light scales at tip.. .8

8(7) Mesonotum with two median grey stripes; sides with broad white stripes in first half of mesonotum; pattern of mesonotum pattern forming a lyre shape. Clypeus with white scales...... Aedes aegypti

- Mesonotum with one median white stripe; sides without white stripes on first half of mesonotum; pattern of mesonotum never lyre shaped. Clypeus bare Aedes albopictus

9(3) Antenna much longer than proboscis; flagellar segment 1 twice as long as clypeus and distinctly longer than segment 2 Deinocerites magnus

- Antenna shorter than proboscis; flagellar segment 1 of antenna subequal or shorter than clypeus and about the same length as second. 10

10(9) Thorax with at most with a few scales along sternopleuron (stp) bristles. Male: palpi about one third the length of proboscis Culex bisulcatus

- Thorax with distinct scale patches on sternopleuron (stp). Male: palpi at least as long as proboscis. ...11

11(10) Hind legs entirely dark scaled, without distinct pale ring over joints of tarsal segments. 12

- $\quad$ Hind legs with distinct pale ring over joints of tarsal segments, sometimes very narrow.
12(11) Upperside of abdomen with large basal white bands; each band distinctly longer in the middle than at the sides. Mesepimeron with large patch of scales medially.

.Culex quinquefasciatus Upperside of abdomen unbanded or at most narrow bands, shortest in the middle. Mesepimeron without large patch of scales medially.

Culex nigripalpus

13(11) Proboscis with a complete white ring in middle. Upperside of abdomen with basal white bands, deepest in the middle (forming triangular spots). Tibia of hind leg with white stripe on underside. Female: palpi with white markings, mesonotum with pattern of white scales ........................Culex bahamensis Proboscis with a usually incomplete white ring. Upperside of abdomen with basal white bands, shortest in the middle; sometimes absent. Tibia of hind leg without white stripe on underside. Female: palpi entirely dark scaled, without white markings, mesonotum without white scales

Culex habilitator

Key to the fourth-instar larvae

Morphological identification key to the fourth instar larvae of mosquitoes of the Dutch Leeward Islands.

1 Respiratory siphon absent; at least some abdominal terga with seta 1 palmate Anopheles albimanus Respiratory siphon present as a strongly chitinized air-tube on segment 8; seta 1 on abdominal terga never palmate.

2(1) Respiratory siphon without pecten teeth; comb scales absent, replaced by 
a large sclerotized plate bearing hairs ...... Toxorhynchites cf. guadeloupensis

- $\quad$ Respiratory siphon with pecten teeth; comb scales present ...3

3(2) Respiratory siphon with at least three tufts.

- $\quad$ Respiratory siphon with only a single tuft

4(3) Head widest at about the level of base of antennae; abdominal segment 10 with two separated sclerotized plates Deinocerites magnus

- Head widest in posterior half; abdominal segment 10 with a single sclerotized plate .5

5(4) Setae of thorax and abdomen stellate Culex bisulcatus

- Setae of thorax and abdomen not stellate. 6

6(5) Respiratory siphon with six aligned tufts; a single pair of anal gills Culex bahamensis

- $\quad$ Respiratory siphon with three to four setae or tufts placed lineally, with one seta or tuft dorsally out of line; two pairs of anal gills... ...7

7(6) Siphon index less than 5 Culex quinquefasciatus

- $\quad$ Siphon index at least 5.5 …………......... 8

8(7) Tufts on respiratory siphon single or double (apical tuft rarely triple

. Culex nigripalpus

- Tufts on respiratory siphon double or triple Culex habilitator

9(3) Ventral brush of segment 10 covers almost the full length of this segment..... Psorophora pygmaea

- Ventral brush of segment 10 covers less than half of length of this segment . .10

10(9) Comb scales arranged in a single row

- $\quad$ Comb scales arranged in multiple rows or a patch.
11(10) Comb scale with a prominent single denticle, with strong preapical spines on sides, giving it a trident like shape Aedes aegypti Comb scale with a single denticle, with a lateral fringe of fine spicules Aedes albopictus

12(10) Saddle on segment 10 forms an incomplete ring; ventral brush with five or six pairs of hairs; comb scales long and slender Aedes busckii

- Saddle on segment 10 forms a complete ring; ventral brush with seven to nine pairs of hairs; comb scale broad

13(12) Saddle on segment 10 with small spicules on caudal fifth. Lateral abdominal hair (6) on segment 3 to 5 usually triple (double to 5 -branched

Aedes taeniorhynchus

Saddle on segment 10 smooth on caudal fifth. Lateral abdominal hair (6) on segment 3 to 5 usually single

Aedes tortilis

\section{Conclusion}

Here we report on the results of a mosquito survey of the Dutch Leeward islands (Sint Maarten, Sint Eustatius and Saba) carried out in 2018 which was the first extensive survey since 1949. Using a variety of collection methods, we observed two new disease vector species for the island of Sint Maarten, Ae. taeniorhynchus and $C x$. nigripalpus, vectors for dog heartworm (Manrique-Saide et al., 2010) and West Nile virus (Barrera et al., 2008), respectively. One previously recorded species, $C x$. habilitator was not observed. We did not find Ae. albopictus. The species richness of the mosquito fauna of Sint Eustatius seems to have decreased compared to previous surveys and is currently dominated by Ae. aegypti and 
Cx. quinquefasciatus, of which the former has also colonized some of the more remote (even brackish) locations previously inhabited by the native $C x$. bahamensis. In contrast, the fauna on Saba has remained quite similar compared to the 1949 survey (Van der Kuyp, 1954), with a species pool dominated by species characteristic of relatively undisturbed forests. Results of this study emphasize the need for regular species inventories of mosquitoes in the Caribbean.

\section{Acknowledgements}

We are greatly indebted to a number of people without whom this study would not have been possible. We are particularly grateful to everyone on the islands for great logistical support, especially Clarisse Buma on Sint Eustatius and Randall Johnson on Saba. Special thanks to Delia Goilo from the Curaçao Biomedical \& Health Research Institute and Emily Khazan from the School of Natural Resources and Environment at University of Florida for joining the expedition team for one week and providing some indispensable help. We thank Dr. Yoosook Lee, Dr. Travis Collier and Allison Weakley from the Vector Genetics Laboratory of the Department of Pathology, Microbiology and Immunology of the University of California for sharing their species records from Saba. This study was supported by a donation by the Gieskes Strijbis fund, the Leiden University LUSTRA+ scholarship and the Saba Sea \& Learn Foundation. We thank Menno Schilthuizen and one anonymous reviewer for the useful comments.

\section{Supplementary material}

Supplementary material is available online at: https://doi.org/10.6o84/mg.figshare.12085773

\section{References}

Adames, A.J. (1971) Mosquito studies (Diptera, Culicidae). XXIV. A revision of the crabhole mosquitoes of the genus Deinocerites. Contrib. Am. Entomol. Inst. 7, 1-154.

Arnell, H.J. (1976) Mosquito Studies (Diptera, Culicidae) XXXIIL A Revision of the scapularis group of Aedes (Ochlerotatus). Contrib. Am. Entomol. Inst. 13, 1-144.

Augier, L.M., Juri, M.J.D. \& Molina, G.A. (2003) Redescripción de la larva y la pupa de Toxorhynchites (Lynchiella) guadeloupensis (Diptera: Culicidae). Rev. la Soc. Entomológica Argentina 62, 99-106.

Barrera, R., Bingham, A.M., Hassan, H.K., Amador, M., Mackay, A.J. \& Unnasch, T.R. (2012) Vertebrate hosts of Aedes aegypti and Aedes mediovittatus (Diptera: Culicidae) in rural Puerto Rico.J. Med. Entomol. 49, 917-921.

Barrera, R., Hunsperger, E., Muñoz-Jordán, J.L., Amador, M., Diaz, A., Smith, J., Bessoff, K., Beitran, M., Vergne, E., Verduin, M., Lambert, A. \& Sun, W. (2008) Short report: First isolation of West Nile virus in the Caribbean. Am. J. Trop. Med. Hyg. 78, 666-668.

Bass, C.M. \& Bass, D. (2011) Aquatic invertebrate community structure in water-filled bracts of Heliconia caribaea (Heliconiaceae) on Saba, West Indies. Living World, J. Trinidad Tobago F. Nat. Club 2011, 60-65.

Belkin, J.N. (1962) The Mosquitoes of the South Pacific (Diptera, Culicidae). Vols. 1 and 2. University of California Press, California.

Belkin, J.N. \& Heinemann, S.J. (1975) Collection records of the project "Mosquitoes of Middle America”. 3. Bahama Is. (BAH), Cayman Is. (CAY), Cuba (CUB), Haiti (HAC, HAR, HAT) and Lesser Antilles(LAR). Mosq. Syst. 7, 367-393.

Belkin, J.N. \& Heinemann, S.J. (1976) Collection records of the project "Mosquitoes of Middle America". 4. Leeward Islands: Anguilla (ANG), Antigua (ANT), Barbuda (BAB), Monserrat (MNT), Nevis (NVS), St. Kitts (KIT). Mosq. Syst. 8, 123-162. 
Belkin, J.N., Heinemann, S.J. \& Page, W.A. (1970) The Culicidae of Jamaica (Mosquito studies. XXI). Contrib. Am. Entomol. Inst. 6, 1-458.

Benedict, M.Q., Levine, R.S., Hawley, W.A. \& Lounibos, L.P. (2007) Spread of the tiger: global risk of invasion by the mosquito Aedes albopictus. Vector-Borne Zoonotic Dis. 7, 76-85.

Berlin, O.G.W. (1969a) Mosquito Studies (Diptera, Culicidae) XVIII. The Subgenus Micraedes of Culex. Contrib. Am. Entomol. Inst. 5, 21-63.

Berlin, O.G.W. (1969b) Mosquito studies (Diptera, Culicidae) XII. A revision of the Neotropical subgenus Howardina of Aedes. Contrib. Am. Entomol. Inst. 4, 1-190.

Berlin, O.G.W. \& Belkin, J.N. (1980) Mosquito studies (Diptera, Culicidae) XXXVI. Subgenera Aedinus, Tinolestes and Anoedioporpa of Culex. Contrib. Am. Entomol. Inst. 17, 1-104.

Boerlijst, S.P., Trimbos, K.B., Van der Beek, J.G., Dijkstra, K.D.B., Van der Hoorn, B.B. \& Schrama, M. (2019) Field evaluation of DNA based biodiversity monitoring of Caribbean mosquitoes. Front. Ecol. Evol. 7, 240.

Bram, R.A. (1967) Classification of Culex subgenus Culex in the New World (Diptera: Culicidae). Proc. United States Natl. Museum 120, 1-122.

Cornel, A., Lee, Y., Fryxell, R.T., Siefert, S., Nieman, C. \& Lanzaro, G. (2012) Culex pipiens sensu lato in California: A complex within a complex? J. Am. Mosq. Control Assoc. 28, 113-121.

Cornel, A.J., Bargielowski, I.E., Collier, T.C., Weakley, A.M., Blosser, E.M., Lanzaro, G.C., Hulshof, K., Braks, M.A.H. \& Lee, Y. (2020) Complete mitogenome sequences of Aedes (Howardina) busckii and Aedes (Ochlerotatus) taeniorhynchus from the Caribbean Island of Saba. Mitochondrial DNA Part B 5, 1163-1164.

Couch, W.J. (2013) Surveillance and spatial characterization of Aedes aegypti in Sint Eustatius, Netherlands Antilles. MSc Thesis.

Darsie, R.F., Taylor, D.S., Prusak, Z.A. \& Verna, T.N. (2010) Checklist of the mosquitoes of the Bahamas with three additions to its fauna and keys to the adult females and fourth instars. J. Am. Mosq. Control Assoc. 26, 127-134.
De Brito Arduino, M., Mucci, L.F., Serpa, L.L.N. \& De Moura Rodrigues, M. (2015) Effect of salinity on the behavior of Aedes aegypti populations from the coast and plateau of southeastern Brazil.J. Vector Borne Dis. 52, 79-87.

De Freitas, J.A., Rojer, A.C., Nijhof, B.S.J. \& Debrot, A.O. (2012) A landscape ecological vegetation map of Sint Eustatius (Lesser Antilles). IMARES, Wageningen UR, rapport C053/12, Wageningen.

De Freitas, J.A., Rojer, A.C., Nijhof, B.S.J. \& Debrot, A.O. (2016) A landscape ecological vegetation map of Saba (Lesser Antilles). IMARES, Wageningen UR, rapport C195/15, Wageningen.

Debrot, A.O., Henkens, R.J.H.G. \& Verweij, P.J.F.M. (2018) Staat van de natuur van Caribisch Nederland 2017: Een eerste beoordeling van de staat (van instandhouding), bedreigingen en managementimplicaties van habitats en soorten in Caribisch Nederland. Wageningen Marine Research, rapport Co86/17, Wageningen.

Dyar, H.G. (1922) The American Aedes of the scapularis group (Diptera, Culicidae). Insecutor Inscitiae Mens 10, 51-6o.

Dyar, H.G. (1928) The Mosquitoes of the Americas. Carnegie Institute, Washington, D.C., Washington, DC.

Egizi, A., Kiser, J., Abadam, C. \& Fonseca, D.M. (2016) The hitchhiker's guide to becoming invasive: exotic mosquitoes spread across a US state by human transport not autonomous flight. Mol. Ecol. 25, 3033-3047.

Eritja, R., Palmer, J.R.B., Roiz, D., Sanpera-Calbet, I. \& Bartumeus, F. (2017) Direct evidence of adult Aedes albopictus dispersal by car. Sci. Rep. 7, 14399.

Farajollahi, A. \& Price, D.C. (2013) A rapid identification guide for larvae of the most common North American container-inhabiting Aedes species of medical importance. J. Am. Mosq. Control Assoc. 29, 203-221.

Faran, M.E. (1980) Mosquito studies (Diptera, Culicidae). XXXIV. A revision of the Albimanus section of the subgenus Nyssorhynchus of Anopheles. Contrib. Am. Entomol. Inst. 15, 1-214. Downloaded from Brill. com04/26/2023 08:04:46AM 
Gaffigan, T. V., Wilkerson, R.C., Pecor, J.E., Stoffer, J.A. \& Anderson, T. (2019) Systematic catalog of Culicidae.URL:www.mosquitocatalog.org(date accessed: December 1, 2019).

Giles, G.M. (1904) Notes on some collections of mosquitoes received from abroad. J. Trop. Med. $7,381-384$.

Glandorf, D.C.M. (2017) Technical evaluation of a potential release of $\mathrm{OX}_{513} \mathrm{~A}$ Aedes aegypti mosquitoes on the island of Saba. RIVM Letter report 2017-0087, Bilthoven.

Goeldi, E.A. (1905) Os mosquitos no Pará reuniáo de quarto trabalhos sobre os mosquitos indigenas, principalmente as espceies que molestam o homem. Memorias do Mus. Goeldi (Museu Paraense), Hist. Nat. e Ethnogr. Pará, Brazil 154 pp.

Gustave, J., Ramdini, C., Pages, N. \& Schaffner, F. (2018) Cle simplifiee des moustiques de Guadeloupe.

Harbach, R.E. (2012) Culex pipiens: Species Versus Species Complex - Taxonomic History and Perspective. J. Am. Mosq. Control Assoc. 28, 10-23.

Harbach, R.E. \& Howard, T.M. (2007) Index of currently recognized mosquito species (Diptera: Culicidae). Eur. Mosq. Bull. 23, 1-66.

Harrington, L.C., Edman, J.D. \& Scott, T.W. (2001) Why do female Aedes aegypti (Diptera: Culicidae) feed preferentially and frequently on human blood? J. Med. Entomol. 38, 411-422.

Henry, M., Francis, L., Asin, V., Polson-Edwards, K. \& Olowokure, B. (2017) Chikungunya virus outbreak in Sint Maarten, 2013-2014. Rev. Panam. Salud Publica 41, e61.

Howard, L.O., Dyar, H.G. \& Knab, F. (1917) The Mosquitoes of North and Central America and the West Indies. Volume 4 (Systematic Descriptions, Part II). Carnegie Institution of Washington, Washington, D.C.

Kraemer, M., Reiner, R., Brady, O., Messina, J., Gilbert, M., Pigott, D., Yi, D., Johnson, K., Earl, L., Marczak, L., Shirude, S., Weaver, N.D., Bisanzio, D., Perkins, T., Lai, S., Lu, X., Jones, P., Coelho, G.,
Carvalho, R., Bortel, W. Van, Marsboom, C., Hendrickx, G., Schaffner, F., Moore, C., Nax, H., Bengtsson, L., Wetter, E., Tatem, A., Brownstein, J., Smith, D., Lambrechts, L., Cauchemez, S., Linard, C., Faria, N., Pybus, O., Scott, T., Liu, Q., Yu, H., Wint, W., Hay, S. \& Golding, N. (2019) Past and future spread of the arbovirus vectors $A e$ des aegypti and Aedes albopictus. Nat. Microbiol. 4, 854-863.

Krol, L., Van der Hoorn, B., Gorsich, E.E., Trimbos, K., Bodegom, P.M. van \& Schrama, M. (2019) How does eDNA compare to traditional trapping? Detecting mosquito communities in South-African freshwater ponds. Front. Ecol. Evol. 7, 260.

Lambin, E.F., Tran, A., Vanwambeke, S.O., Linard, C. \& Soti, V. (2010) Pathogenic landscapes: Interactions between land, people, disease vectors, and their animal hosts. Int.J. Health Geogr. 9, 54 .

Lane, J. (1953) Neotropical Culicidae, Vol. I and II. University of São Paulo, São Paulo.

Leslie, T.E., Carson, M., Van Coeverden, E., De Klein, K., Braks, M. \& Krumeich, A. (2017) An analysis of community perceptions of mosquito-borne disease control and prevention in Sint Eustatius, Caribbean Netherlands. Glob. Health Action 10, 1350394.

Leslie, T.E., Martin, N.J., Jack-Roosberg, C., Odongo, G., Beausoleil, E., Tuck, J., Raviprakash, K. \& Kochel, T.J. (2014) Dengue serosurvey in Sint Eustatius. PLoS One 9, e95002.

Lounibos, L.P. (2002) Invasions by insect vectors of human disease. Annu. Rev. Entomol. 47, 233-266. Ludlow, C.S. (1905) Mosquito notes - No. 4. Can. Entomol. $37,385-388$.

Manrique-Saide, P., Lenhart, A., Ceh-Pavía, E., Guillermo-May, G., Escobedo-Ortégon, J., BolioGonzález, M., Sauri-Arceo, C. \& Dzib-Florez, S. (2010) Incrimination of the mosquito, Aedes taeniorhynchus, as the primary vector of heartworm, Dirofilaria immitis, in coastal Yucatan, Mexico. Med. Vet. Entomol. 24, 456-46o. 
Matheus, S., Chappert, J.-L., Cassadou, S., Berger, F., Labeau, B., Bremand, L., Winicki, A., Huc-Anais, P., Quenel, P. \& Dussart, P. (2012) Virological surveillance of dengue in Saint Martin and Saint Barthelemy, French West Indies, using blood samples on filter paper. Am. J. Trop. Med. Hyg. $86,159-165$.

Mohammed, H., Evanson, J., Revan, F., Lee, E., Krecek, R.C. \& Smith, J. (2015) A mosquito survey of the Twin-Island Caribbean Nation of Saint Kitts and Nevis, 2010. J. Am. Mosq. Control Assoc. 31, 360-363.

Neiderud, C.-J. (2015) How urbanization affects the epidemiology of emerging infectious diseases. Infect. Ecol. Epidemiol. 5, 2706o.

PAHO (2020) Reported cases of dengue fever in The Americas. URL: http://www.paho.org/data/ index.php/en/mnu-topics/indicadores-dengue -en/dengue-nacional-en/252-dengue-pais-anoen.html (date accessed: March 21, 2020).

Ponlawat, A. \& Harrington, L.C. (2005) Blood feeding patterns of Aedes aegypti and Aedes albopictus in Thailand. J. Med. Entomol. 42, 844-849.

Pratt, H.D. (1969) Key to the Culicidae of Puerto Rico.

Reiter, P., Amador, M.A., Anderson, R.A. \& Clark, G.G. (1995) Short report: Dispersal of Aedes aegypti in an urban area after blood feeding as demonstrated by rubidium-marked eggs. Am. J. Trop. Med. Hyg. 52, 177-179.

Richardson, B.A. \& Richardson, M.J. (2014) Bromeliad invertebrate communities on Saba, Netherlands Antilles. Caribb. Nat. 14, 1-12.

Richardson, M.J., Richardson, B.A. \& Srivastava, D.S. (2015) The stability of invertebrate communities in bromeliad phytotelmata in a rain forest subject to hurricanes. Biotropica 47, 201-207.

Rozeboom, L.E. \& Gabaldon, A. (1941) A summary of the "tarsimaculatus" complex of Anopheles (Diptera: Culicidae). Am. J. Hyg. 33, 88-100.

Rueda, L.M. (2008) Global diversity of mosquitoes (Insecta: Diptera: Culicidae) in freshwater. $\mathrm{Hy}$ drobiologia 595, 477-487.
Schaffner, F. (2003) Les moustiques de Guadeloupe. Rapport d'Entente Interdepartementale pour la Demoustication, Montpellier, France.

Stone, A. (1967) A synoptic catalog of the mosquitoes of the World, supplement III (Diptera: $\mathrm{Cu}$ licidae). Proc. Entomol. Soc. Washington. 69, 197-224.

Van der Kuyp, E. (1948) Mosquito records of the Netherlands Windward Islands. Am. J. Trop. Med. Hyg. 28, 747-749.

Van der Kuyp, E. (1949) Annotated list of mosquitoes of the Netherlands Antilles including French St. Martin, with a note on Eutriatoma maculata on Curaçao and Bonaire. Doc. Neerl. Indones. Morbis Trop. 1, 69-70.

Van der Kuyp, E. (1953) Culicinae from the Netherlands Antilles and some other Caribbean localities. Stud. Fauna Curaçao other Caribb. Islands 4, 144-148.

Van der Kuyp, E. (1954) Mosquitoes of the Netherlands Antilles and their hygienic importance. Stud. Fauna Curaçao other Caribb. Islands 5, 37-114.

Veenenbos, J.S. (1955) Soil and Land Capability Survey of St. Maarten, Statia, Saba. Foundation for Scientific Research in Surinam and the Netherlands Antilles, No. 11, Utrecht.

Verdonschot, P.F.M. \& Besse-Lototskaya, A.A. (2014) Flight distance of mosquitoes (Culicidae): A metadata analysis to support the management of barrier zones around rewetted and newly constructed wetlands. Limnol. - Ecol. Manag. Inl. Waters 45, 69-79.

Verweij, P. (2010) Vegetation map of St.Maarten. URL: http://www.dcbd.nl/document/vegeta tion-map-stmaarten (date accessed: April 2, 2018).

WHO (2017) Vector-borne diseases. Geneva World Heal. Organ. URL: https://www.who.int/en/ news-room/fact-sheets/detail/vector-bornediseases (date accessed: February 13, 2019).

Wilkerson, R.C., Linton, Y.M., Fonseca, D.M., Schultz, T.R., Price, D.C. \& Strickman, D.A. (2015) 
Making mosquito taxonomy useful: A stable classification of tribe Aedini that balances utility with current knowledge of evolutionary relationships. PLoS One 10, 1-26.
RECEIVED: 20 JANUARY 2020 | REVISED AND ACCEPTED: 31 MARCH 2020

EDITOR: R. VONK 